\title{
Josefina Plá e a conformação do conto paraguaio: a desolação de pertencer a dois mundos
}

\author{
Josefina Plá and the conformation of the Paraguayan tale: \\ the desolation of belonging to two worlds \\ Maria Josele Bucco Coelho \\ Universidade Federal do Paraná - Curitiba, PR, Brasil
}

\begin{abstract}
Resumo: Partindo da percepção defendida por Bernd (2012) de que as mobilidades migratórias transculturais exercem uma influência significativa nas práticas literárias, este trabalho busca evidenciar o papel desempenhado pela escritora Josefina Plá (1903-1999) no sistema literário paraguaio, tracejando a importância por ela assumida na conformação da narrativa contemporânea dessa comunidade literária. Por meio da análise do conto Sesenta listas (1981), busca-se esquadrinhar a potência transculturadora/fagocitadora das narrativas de Josefina Plá, ao mesmo tempo em que se faz aflorar a violência engendrada pela colonialidade na comunidade cultural do Atlântico Sul.
\end{abstract}

Palavras-chave: Literatura paraguaia; Conto contemporâneo; Mmobilidade transcultural; Fagocitação; Josefina Plá

\begin{abstract}
Based on the perception defended by Bernd (2012) that transcultural mobilities exert a significant influence on literary practices, this paper seeks to highlight the role played by the writer Josefina Plá (1903-1999) in the Paraguayan literary system, describing its importance in the conformation of contemporary narrative of this literary community. Through the analysis of the short story Sesenta listas (1981), it seeks to explore the transcultural / phagocytic power of Josefina Plá's narratives, at the same time as the violence engendered by coloniality in the cultural community of the South Atlantic.
\end{abstract}

Keywords: Paraguayan literature; Contemporary tale; Transcultural mobility; Phagocytosis; Josefina Plá

\begin{abstract}
Yo quiero 'ser siempre' pero al propio tiempo me resisto a cambiar. [...] Multiplicándome sin repetirme. Estar dejando de ser constantemente lo que no se llegó a ser. Ser lo que nunca alcanza a ser lo que permanece. Que no llegará a evadir este rodar que ovilla la náusea de la distancia.
\end{abstract}

(Josefina PlÁ)

A tarefa de delinear o lugar que um escritor ocupa dentro de um sistema de produção cultural é, invariavelmente, perigosa. Operam, nessas circunstâncias, mais que as tradicionais compilações e inventários de dados críticos, uma vez que se conjugam as relações sociopolíticas e geoculturais de uma dada territorialidade que precisam ser represadas, temporalmente, para ser entendidas. Além disso, há de se acrescer ainda a consciência do levante, inevitável, da arena discursiva que se conforma e que exige, por conseguinte, o estabelecimento de uma espécie de ritual de controle, seleção, organização e redistribuição, classificação.

Nesta perspectiva, circunscrever a inserção de Josefina Plá dentro do sistema literário rio-platense exige um viés intervalar, uma vez que concorrem, em sua produção literária, "dos sistemas: la cultura hispánica peninsular y la cultura hispano-mestiza paraguaya" (FERNÁNDEZ, 2000, p. 09). Há de se considerar, portanto, as amalgamas, 
os des(encontros) e as contradições aportados por essa convergência, uma vez que América Latina, "por su constitución histórico-estructuralmente dependiente dentro del actual patrón de poder, ha estado [desde sus comienzos] y [durante] todo este tiempo, constreñida a ser el espacio privilegiado del ejercicio de la colonialidad del poder" (QUIJANO, 2005, p. 10).

Dentro dessa conjuntura, Josefina Plá é tomada, quase miticamente, como um dos pilares da narrativa paraguaia por Pérez Maricevich para quem, sem a presença dela, a história desse gênero na literatura paraguaia seria uma fabulação. Josefina, se não existisse, deveria ser um personagem a ser inventado sob pena de não se encontrar "modo de armar el rompecabezas, hallándose por doquier con hilos sueltos pero sin jamás dar con la punta del ovillo" (PÉREZ MARICEVICH, 1983, p. 05). Josefina desponta na produção literária paraguaia, deste modo, envolta em ares fundacionais e precursores.

No entanto, há de se reconhecer a complexidade desse lugar por ela ocupado, uma vez sua principal característica é a presença-ausência da narrativa em território paraguaio. Esse "personagem" inserido na história da literatura paraguaia, ao ser artífice desse enredo polarizado, parece obedecer à tese defendida por Piglia, para quem, "um conto conta duas histórias" (PIGLIA, 2004, p. 87). E é na esteira dessa analogia que se vislumbra como o precursionismo de Josefina Plá conforma a história da narrativa paraguaia, dividida entre duas perspectivas uma que se apresenta de forma mais visível, sistematizada e aparente enquanto que a outra, secreta, vai sendo constituída enigmaticamente dentro do mesmo relato, mas de modo elíptico e fragmentado. Entretanto, a ambas corresponde um sistema de causalidade que pode ser, tal qual um novelo de lã, desenrolado.

O primeiro, dentre os muitos nós a serem desfeitos, diz respeito à definição da produção literária narrativa em território paraguaio como uma suposta "incógnita" De certa forma, o uso da expressão território, nesse

\footnotetext{
1 A história do uso do termo incógnita para referir-se à literatura paraguaia é explorada por Peiró Barco (2001, p. 60-67), em sua tese de doutorado. Segundo o levantamento histórico por ele realizado, Luis Alberto Sánchez, na obra Historia de la literatura americana (Desde los origenes hasta 1936) usa a expressão 'incógnita' para definir a produção do Paraguai. Essa percepção passa, posteriormente, a ser repetida inúmeras vezes, tornando-se uma espécie de rótulo ao longo da história da crítica literária latinoamericana. Essa mesma denominação é explorada, posteriormente, em 1945, pelo paraguaio Arnaldo Valdovinos que publica uma obra intitulada La incógnita del Paraguay - uma clara provocação à expressão usada pelo peruano. Em 1951, Walter Rey estudou a poesia Paraguaia em uma obra que recupera, uma vez mais, essa mesma ideia de 'incógnita': La poesía paraguaya. Historia de una incógnita. Sindulfo Martínez alude a famosa incógnita no capítulo XXI de Hombres y pasiones e Hugo Rodríguez Alcalá se refere à renomada incógnita em um estudo sobre Augusto Roa Bastos publicado em 1962. Então, quando se trata das publicações efetivadas em solo paraguaio, parece que não há uma história da literatura paraguaia, mas sim a história da incógnita paraguaia.
}

contexto, é essencial para articular como se cristalizou essa ideia já que, até as primeiras décadas do século XIX, a divisão política da região obedecia a critérios diferentes daqueles que conformam as fronteiras nacionais hoje vigentes, pois a região pertencia ao Virreinato del Río de la Plata - dissolvido em 1814. Por essa razão, quando Menéndez Pelayo (1948, p.301) afirma não existir uma literatura paraguaia colonial é rebatido, acertadamente, por Rodríguez Alcalá (1999, p.09) que justifica tal situação pelo fato de que em Buenos Aires - capital do vice-reino - convergiam as publicações das obras no período. A territorialidade que hoje conforma a nação paraguaia era, portanto, parte do vice-reino e em sua extensão, carente de centros urbanizados, proliferavam fortificações. Estabelecidas as fronteiras nacionais modernas, o território paraguaio ficou carecendo de um passado literário.

Desfeita a primeira ponta do nó, é preciso observar, então, que essa "falta de um passado literário paraguaio" ${ }^{2}$ " se deve a essa especificidade geocultural que acarretou na disseminação de fortes e missões no território paraguaio em detrimento da formação de cidades e, consequentemente, no fortalecimento da escrita e publicação de obras na capital do vice-reino, Buenos Aires.

O desarmamento do segundo nó requer um giro ainda mais incisivo que se assenta na (des)constituição da equação oralidade - escrita como referencial para o que se considera - e se sistematiza - como literatura. $\mathrm{O}$ apagamento do passado de uma história da literatura no Paraguai engendra, concomitantemente, o apagamento de toda uma tradição de origem indígena fundada na oralidade. Roa Bastos ao tratar dessa "literatura ausente" reconhece, antiteticamente, a presença de outra que, naquele momento, não pode ser considerada como parte da "temple de una colectividad, de sus modos de ser, de su ámbito físico y sociocultural, todo eso que de una manera abstracta se suele llamar identidad nacional" (1997, p.498). Esse entendimento, datado, revela os paradigmas que justificam o postulado defendido sobre a ausência de um passado literário que é, pelo próprio escritor, de certa forma, subvertido ao descrever a forte presença da tradição oral:

En un sentido general, sin embargo, cabría suponer que las carencias de una literatura escrita (nótese que hablo exclusivamente del género narrativo), determinadas por circunstancias históricas y socioculturales, pueden ser compensadas por la presencia de una vigorosa literatura popular de tradición oral. Esta no sería entonces solamente la expresión de hechos

\footnotetext{
2 Essa é uma afirmação que foi feita por Josefina Plá, em 1962. Foi reiterada, posteriormente, por Roa Bastos. Segundo ela, no período colonial floresceu apenas a historiografia e, apenas entrado o século XX é que se consolida a narrativa no Paraguai (PLÁ, 1962, p. 68-90).
} 
culturales producidos y consumidos por los sectores social y económicamente marginalizados; no sería tampoco, únicamente, la manifestación concebida como el producto de la oposición entre una cultura de masas y una cultura de élites, sino que cumpliría un rol comunicacional y de interacción social más amplio entre los distintos sectores de la colectividad (ROA BASTOS, 1997, p. 499).

Percebe-se, portanto, que a presença-ausência da história de um passado literário paraguaio poderia somar-se à extensão das incógnitas que ainda estão à espera de ser desveladas por meio de uma arqueologia do silêncio. Assim, a forte tradição oral que Roa Bastos menciona - fruto da presença indígena - sofre um apagamento e não pode inserir-se dentro dos esquemas tradicionais do sistema literário. Isso porque a equação oralidade-escritura, tal qual aponta Haveloch (1995) se manteve, ao longo dos tempos, pendida para a expressão escrita que, salvo manifestações isoladas, constituiu a base tanto do que se considerava como do que se estudava como literatura.

A literatura aborígene - que em grande parte era religiosa - perdeu-se, e o que pôde ser conservado, o foi graças à tradição oral. É significativo que no Paraguai, onde os missionários desenvolveram sua empresa cultural máxima na língua do país, não se tenha transcrito uma só produção de origem indígena sob o impulso dos padres da Companhia. Também não foram difundidas as diferentes crônicas feitas pelos escritores dos povos subjugados, seguramente porque davam uma versão heterodoxa dos fatos (SAGUIER, 1979, p. 07).

Apenas adentrado o século XX é que a oralidade passa a ser reconsiderada formalmente nos estudos acadêmicos, engendrando um interesse pela palavra poética oral. Esse predomínio da escrita não pode ser considerado como aleatório. As escolhas epistêmicas são responsáveis pela produção de discursos na sociedade que, conforme afirma Foucault, "tem por função conjurar seus poderes e perigos, dominar seu acontecimento aleatório, esquivar sua pesada e temível materialidade" (1999, p. 09). Por essa razão, o papel secundário desempenhado pela poesia oral ou palavra poética nas sociedades ocidentais - e no caso do Paraguai - se deve, em grande parte, à vinculação destas formas de expressão a um extrato da população considerada como inculta, tratada como "literatura de pessoas que não sabiam ler nem escrever" (FERNANDEZ, 2007, p. 24). Assim, parte do extrato da população - indígena e mestiça - sem meios de acesso à expressão escrita, esteve confinada à subalternidade, à falta de um lugar de enunciação por não dispor dos códigos exigidos pela cultura escrita.
O terceiro nó a ser desfeito não revela um apagamento - tal qual a situação geocultural ou a desconsideração da produção de tradição oral - mas torna visível um posicionamento que foi crucial para o isolamento da produção literária paraguaia e que reflete uma das facetas dessa comunidade cultural que foi plasmada como "particularismo" - uma espécie de ideologia que se disseminou no século XIX e que objetivava acentuar a idiossincrasia do povo paraguaio. Esse terceiro nó talvez seja um dos mais complexos porque está fundado na defesa de uma postura isolacionista e na crença "de no tener por qué contar con los demás, ya por excesiva autoestima, ya por menosprecio del prójimo, lo que supone la pérdida de la noción de limites pero la adquisición de un sentimiento de independência" (PEIRÓ BARCO, 2001, p. 22).

Fatalmente, essa percepção se contrapõe ao princípio aglutinador que envolvia a noção de pertença a uma territorialidade mais abrangente, como a rio-platense para centrar-se em uma busca de rivalizar ${ }^{3}$, literalmente, com as nações vizinhas em franco processo de constituição das identidades nacionais, já que pressupunha um rechaço à influência externa, sempre considerada "como negativa y destructora de los valores más puros del ser nacional" (PEIRÓ BARCO, 2001, p. 23).

Também se distancia do afã nacionalista romântico preconizado pelos sistemas literários vizinhos. A independência identitária buscada no Brasil, por exemplo, pela frutífera produção romântica estava centrada na busca da síntese, da idealização do encontro com o europeu. Em um movimento de autopreservação, o particularismo paraguaio se apresenta, desde nossa perspectiva, como um movimento radical de exaltação do local. Contraditoriamente, essa especificidade foi considerada como um dos fatores que retardaram o desenvolvimento da literatura na região porque essa postura, responsável pelo incentivo do uso da língua guarani, acabou coadunando para o lento desenvolvimento da narrativa paraguaia. Isso porque o bilinguismo se instaurou de forma conflitante e paradoxal. Com uma população sem acesso às letras, o guarani se tornou, ao mesmo tempo, o estandarte da diferença e o motivo da falta de produção literária - uma vez que a língua espanhola permaneceu como o código valorado.

\footnotetext{
O que se deve observar é que imperava no Paraguai uma busca exagerada de isolar-se dos países vizinhos. Uma necessidade de autodefinição que, de um lado, gerou um sentimento patriótico profundo e por outro, teve consequências drásticas vislumbradas na imensa quantidade de conflitos e guerras que o país se envolveu, como por exemplo, a Guerra do Paraguai ou Gran Guerra (1864-1970) e a Guerra do Chaco (19321935). Esses conflitos são considerados como decisivos para entender como se efetivou a dissonância existente entre a produção literária do Paraguai e de seus países vizinhos, pois não houve desenvolvimento da imprensa que somada ao analfabetismo imperante, impossibilitou a formação de uma classe de leitores. A política isolacionista iniciou com Francia, seguindo com os Lopez. Foi esse particularismo, juntamente com a Guerra da tríplice Aliança que impediram o desenvolvimento cultural do país no mesmo ritmo do resto do continente.
} 
As primeiras narrativas se desenvolvem no Paraguai, portanto, ladeadas pelo maniqueísmo político preconizado por Francia e pelos Lopez com suas políticas de particularismo de cunho romântico. A obra Ignacia (1905) de José Rodríguez Alcalá é considerada, nesse ínterim, como a primeira narrativa paraguaia. Nesse período, predominam duas principais correntes - realista crítica e realista costumbrista. E aí se apresenta o quarto nó a ser desprendido. Seus dois principais representantes José Rodríguez Alcalá e Rafael Barrett - são estrangeiros. Para Peiró Barco (2001) há uma dissonância já que eles não publicaram apenas no Paraguai e deveriam ser vistos como imigrantes.

Essa observação nos permite afirmar, sem constrangimentos, a falibilidade dos sistemas tradicionais para pensar as produções artísticas-culturais-literárias. Trata-se de uma rasura que compõe esse delicado processo de negociação de heranças e pertencimentos. A visão tradicional do fenômeno literário que desconsidera as mobilidades se reveste de um matiz de "neoparaguaidade", que é, de certa forma, um apelo nacionalista ultrapassado.

A riqueza e intensidade das mobilidades que atravessaram/atravessam o fazer literário paraguaio são, portanto, o fio ariadniano que nos permite vislumbrar, desde uma perspectiva mais fluída, como a produção literária dessa territorialidade se investe de traços advindos desde os mais diversos lugares. Josefina Plá, nesse contexto, perfaz mais uma risca desse intricado tecido.

Tergiversando esses grandes nós estão implícitos os motivos que explicitam o apagamento, a invisibilidade, a incógnita da produção literária paraguaia. A lógica e a especificidade das relações de poder e os conflitos que entre eles orbitam balizam e relativizam o protagonismo concedido a Josefina Plá. Não se trata, obviamente, de negar o papel exercido por ela nem mesmo o simbolismo que sua presença transculturada e intersticial confere à narrativa paraguaia, mas de evidenciar a 'segunda história' - ocultada em meio a essas relações de poder.

\section{A força renovadora da narrativa de Josefina Plá}

O que chama a atenção dentro desse contexto, no entanto, é a força renovadora da narrativa de Josefina Plá. Enquanto persistia a descrição romantizada dos heróis das guerras ${ }^{4}$, ela preconiza o realismo crítico que seria, posteriormente, adotado por Roa Bastos e os

\footnotetext{
4 Para Peyró Barcó (2001), a incipiência da produção literária paraguaia se dá por um afã de manter-se atrelado a um passado histórico nada heroico, mas transformado, romanticamente, pelos intelectuais. Nesse processo de construção dessa comunidade imaginada, esses intelectuais se dedicaram ao trabalho historiográfico baseado no endeusamento do mariscal López, retendo toda a energia em provar esse 'ser paraguaio' heroico e vitimado pelos países vizinhos.
}

demais integrantes do grupo de 1940. Essa é a chave da renovação e a importância de Josefina Plá para as letras paraguaias que, conforme Mateo del Pino "no solo ha sabido elevar la cultura de su país de adopción, sino que a la vez ha propiciado la revisión y puesta al día de ésta" (2002). De certa forma, ela foge do estereótipo de elucidar as grandezas e feridas das guerras anteriores para debruçar-se sobre a dura realidade em que os paraguaios se encontram - em especial, as mulheres que, suportando o peso dos conflitos, viviam sob o jugo de uma estrutura patriarcal e machista. Sendo pobre e mestiça, a mulher paraguaia se investia de uma multi-colonialidade.

Neste contexto, a produção contística de Josefina Plá pode ser mais bem compreendida se pensada desde uma perspectiva temática. Isso porque, até a década de 1950 , Josefina Plá escreveu contos de forma esporádica que eram publicados na Revista Alcor. Posteriormente, seus contos foram publicados em distintas antologias, revistas e periódicos paraguaio. Mateo del Pino faz uma extensa e minuciosa compilação das publicações 'aleatórias' dos contos de Josefina Plá, descrevendo que seus relatos fizeram parte de antologias como Crónicas del Paraguay (1969); Los narradores. Revista del PEN Club del Paraguay (no 3), Ediciones Comuneros, Asunción, 1979; Panorama del cuento paraguayo (T.I), Tiempo Editora, Asunción, 1988. Além disso, os contos infantis, Cuatro burros y cuatro coles y El gigante invisible, foram publicados em Leyendo cuentos en la plaza, Ed. El Lector, Asunción, s/f. Em 1990, Ramón Bordoli Dolci compila em Canto y cuento, Arca Editorial, Montevideo, 1993, nove contos de Josefina: La mano en la tierra, El espejo, El canasto, Nandurié, Mascaritas, Eternidad, Prometeo, La muralla robada e Aborto. Somente em 1996 é que temos uma edição completa, que reúne toda a producao contistica de Josefina Plá feita por Miguel Angel Fernández, publicada pela Editora El lector que apresenta, ainda, contos inéditos: El arbolito, La sombra del maestro e El rostro y el perro.

Assim, um ordenamento cronológico não supre essa peculiaridade já que muitos contos, de acordo com Fernández, "fueron escritos tempranamente e reelaborados posteriormente" (2000, p. 11). A própria escritora, ao refletir sobre seu processo criativo adverte que

La narrativa es uno de mis modos de expresarme; no una vertiente exclusiva. Escribo cuentos cuando necesito hacerlo (hace diez años que no los escribo). Escribo cuentos por temporadas, como necesito por temporadas escribir versos o hacer cerámica. Podría decirse que tengo fases como la luna, sin por eso ser más lunática que cualquier otro escritor que se respete. Porque creo en realidad que en todo escritor se da esa tenencia cíclica: al que menos, tiene dos fases: la activa y la del dolce far niente. Yo, esta, por desgracia para mí y para todos, no la conocí nunca (PLÁ, 1981, p. 10). 
Assim, os quatro livros de contos publicados em um lapso de vinte e sete anos - La mano en la tierra (1963), El espejo y el canasto (1981), La pierna de Severina (1983) e La muralla robada (1989) concentram relatos que a crítica especializada organizou em distintas perspectivas: o realismo crítico, onde podem ser encontrados contos "fatalistas e de desarraigo" em que predomina conteúdo de teor crítico social, em ambiente popular paraguaio. Neles, se sobressai o protagonismo feminismo. Os contos de desarraigo retomam momentos iniciais da colonização e a busca de fincar raízes em um ambiente hostil e desconhecido. Os relatos folclóricos - em que são compiladas anedotas de origem popular e relatos tomados da oralidade, ou seja, "se trata de eso que se llama folklore naciente y que acaso llegase a nacer del todo, si la tecnología, avanzando con botas de siete leguas por las zonas rurales, no diluye las probabilidades de esa cristalización folklórica" (PLÁ, 1983, p. 06). Há também os contos oníricos, também chamados de simbólicos ou fantásticos que, a modo do exorcismo cortazariano, referem-se a devaneios vividos e plasmados literariamente

Me resulta difícil interpretar estos como no sea si los doy como deseo de eliminar el residuo de angustia irreductible que queda en el fondo de ciertas experiencias vitales; por lo demás la mayoría de esos cuentos han sido escritos sobre el patrón de un sueño auténtico [...]. Podría decir que si yo supiese el exacto significado de esos cuentos, posiblemente no los hubiera escrito. En verdad, la única transformación que esos cuentos suponen sobre el sueño original reside en la importancia que en ellos adquiere la impresión final del sueño, dando atmósfera a todo el cuento (PLÁ apud BORDOLI DOLCI, 1984, p. 537).

Por último, curiosamente, há uma classe de contos que Josefina Plá denomina de criaturas. São textos que circulam e transitam entre diversas publicações. Pode-se considerá-los como relatos consagrados pela crítica, mas o interessante é o caráter obsessivo com que são retomados periodicamente nas antologias. Para além dessa primeira percepção, é preciso considerar que o termo 'criatura' - usado por Josefina para congregá-los - em espanhol não é usado apenas para designar as coisas criadas por Deus ou algum tipo de ser fantástico. Criatura, em espanhol, é um termo usado para nomear o filho ou a criança recém-nascida. De certa forma, as criaturas de Josefina Plá - La mano en la tierra (1963), La pierna de Severina (1983), Prometeo (1981), La niñera mágica (1981), El espejo (1981), El canasto (1981), Sise (1969), entre outros- constituem uma série de filhos prediletos que representam o núcleo de sua produção contística.
Poderíamos ainda inserir, nesse momento, a forma como esses contos se inserem dentro da constítica paraguaia, dividida entre duas grandes correntes a partir de 1950: a esteticista e a mundonovista ${ }^{5}$. A modalidade que ficou conhecida como esteticista se centrava na exploração da linguagem, na busca pelo belo, na exaltação do exotismo (do indígena ou do paraguaio), mas sem qualquer aprofundamento na realidade social. Já a modalidade denominada mundonovista estava concentrada na realidade paraguaia, que com um claro nacionalismo paraguaio tinha um propósito patriótico, distanciando-se da reflexão crítica.

No entanto, este estudo interessa frisar o giro operado por Josefina quando ela, deliberadamente, percebe, assume e dissemina o Paraguai mestiço, híbrido e transculturado. Se antes havia a pretensão de manter-se isolado em certo particularismo, é com a chegada de uma espanhola que se cria o ambiente propício para a renovação. Se antes a intelectualidade paraguaia reprovava a cultura indígena e via nela uma forma de atraso, Josefina Plá, ao contrário, incorpora e denuncia os abusos da colonialidade, mostrando que aceitar a diferença e a pluralidade era um dos caminhos para a criação de uma identidade riscada, isto é, composta por inúmeras nuances: complexa, híbrida e relacional.

Fernández (2012) coaduna com essa proposição ao afirmar que o fazer literário de Josefina Plá assume uma complexidade porque sua adesão ao realismo crítico não é apenas uma escolha estética, mas advém do processo de estranhamento causado por um intenso entrechoque cultural. É Josefina, a deslocada que, tal qual o viajante, observa e se assombra frente à novidade da diferença? $\mathrm{O}$ crítico e poeta paraguaio, afirma que o trabalho artístico dela se dará no ponto de encontro de dois sistemas: a cultura hispânica peninsular e a cultura hispano-mestiça paraguaia e que

o 'realismo critico' de Josefina Plá, não é, portanto, de raiz ideológica, mas de caráter estrutural. Dito de outra maneira, origina-se na perspectiva, na distância que separa a autora do universo semântico do entorno, do qual apesar de tudo, forma parte e ao qual vem somar, integrar, seu próprio universo através de suas produções literárias (FERNANDEZ, 2012, p. 12, grifo meu).

\footnotetext{
5 Duas correntes dominam a contística paraguaia a partir de 1950. A modalidade que ficou conhecida como esteticista se centrava na exploração da linguagem, na busca pelo belo, na exaltação do exotismo (do indígena ou do paraguaio), mas sem qualquer aprofundamento na realidade social. Já a modalidade denominada mundonovista estava concentrada na realidade paraguaia, que com um claro nacionalismo paraguaio tinha um propósito patriótico, distanciando-se da reflexão crítica.
} 
Poderíamos afirmar que no centro do processo criativo de Josefina Plá há um forte componente etnográfico. Sua inserção intervalar em uma cultura diferenciada a obriga, de certa forma, a ser uma atenta observadora - e coletora - do ethos paraguaio, plasmando-o literariamente. Essa perspectiva, no entanto, ainda que elucidativa do entrelugar ocupado por Josefina Plá pode ser enriquecida pela consideração da natureza dessa transculturação.

No jogo estabelecido pelos (des)encontros culturais sistematizados pelos estudiosos das Américas, prevalece o domínio da visão ocidental sobre as culturas nativas. Os produtos desses encontros, transculturados/ sincréticos/mestiços carregam uma marca de colonialidade onde prepondera o eurocentrismo, estabelecendo a subalternidade das culturas originárias. Nessa perspectiva, o significado do transcultural se estabelece tendo como centro de gravidade a Europa, uma realidade ontológica que se instaura como paradigma comparatista e mantém as assimetrias do passado colonial. Para Shohat e Stam (2006), essa visão eurocêntrica está fundada na percepção de que

A produção cultural e material dos 'outros' pode ser apropriada e suas conquistas negadas, enquanto o ato de apropriação que marca a antropofagia cultural europeia é glorificado. O ocidente, como afirma Barbara Kirshenblatt-Gimblett, 'rompe os laços entre as formas e suas origens, converte essas formas em influências, leva tais influências ao centro, deixa as origens à margem e se parabeniza por ser tão cosmopolita' (2006, p. 22).

Ora, no caso de Josefina Plá, se opera um processo inverso. Sua produção narrativa, transcultural, orbita ao redor da fagocitação, isto é, de uma apropriação ao inverso. Conforme aponta o filósofo argentino Rodolfo Kusch,

La aculturación se produce en un plano material, como la arquitectura o vestimenta, en otros órdenes pudo haberse producido un proceso inverso, diríamos de fagocitación' [...]. La fagocitación se da en un terreno de imponderables [...]. Es cuando tomamos conciencia de que algo nos impide de ser totalmente occidentales aunque nos lo propongamos' (2000, p. 179-180).

$\mathrm{Na}$ lógica americanista de Kusch, o eurocentrismo é invertido na medida em que são os elementos nativos que se impõe fortemente na constituição da identidade relacional e transculturada. E essa é uma risca indelével. Antes sim, apresenta-se como um elemento de desestruturação da hierarquia epistemológica e articula uma nova configuração dos conhecimentos de/sobre a produção literária paraguaia (que poderia ser estendida a outras práticas artísticas das Américas). Nessa nova configuração, são os elementos americanistas que se sobressaem tornando-se o vértice sob o qual se forjam os produtos transculturais. E como se há de imaginar, no sistema expressivo de Josefina Plá, esse jogo de fagocitação transcultural é complexo. O conto Sesenta listas - escrito em 1953 e publicado em 1981 na obra El espejo y el canasto - implode os antigos binarismos - opositivos, reguladores e formadores de pares dicotômicos - e flagra o processo de fagocitação transcultural nas Américas que tão bem representa a narrativa platiana.

\section{Sessenta listras fagocitadas: colonialidade e transculturação}

O conto Sesenta listas ${ }^{6}$ faz parte da primeira fase da produção narrativa platiana, fixada entre 1945 a 1963. Nesse período, Josefina transitava entre diversas práticas artísticas, dedicando-se intensivamente ao teatro, à cerâmica e à poesia, por isso os contos ficaram à espera de um momento oportuno para serem publicados. Essa é a razão pela qual, ao prologar o volume em que Sesenta Listas está incluído, ela reforça que esses textos "son en efecto los documentos de un anhelo de expresión que el silencio circundante, la imposibilidad de comunicación, no consiguieron aplacar" (PLÁ, 2000, p. 53).

Os dois signos que dão título ao livro - 'espejo' e 'canasto'- foram retirados de contos homônimos da antologia, convertendo-se em duas potentes imagens que funcionam como chaves interpretativas das narrativas que o volume encerra. Em El espejo (PLÁ, 2000, p. 55-68), conto que abre a antologia e antecipa o canônico El Otro borgiano, se vislumbra o embate psicológico diante da iminência da morte refletida no espelho de um quarto já esquecido. O declínio do corpo, as relações familiares fragmentadas e o abandono são insígnias atravessadas pela dolorosa experiência de ver-se e de enfrentar-se.

Já no conto que fecha a coletânea - El canasto (PLÁ, 2000, p. 155-160) - divisa-se o protagonismo de um incômodo cesto feito de taquara deixado na entrada de um ônibus coletivo, cujo pertencimento ninguém adivinha. Dentro dele - erva-mate, poncho, roupas sujas, sacos de estopa - elementos que se atrelam à experiência dos povos originários e que provocam a ira naqueles passageiros que necessitam seguir adiante e chegar a um destino. Ao redor dele, as acusações silenciosas e a desconfiança de que qualquer um poderia ser o dono daquela moléstia. $O$ cesto é símbolo do estranhamento e da negação da pertença indígena.

\footnotetext{
6 Para fins de referência, será usada a sigla SL para referir-se ao conto PLÁ, Josefina. Sesenta listas. In: Cuentos Completos. 2. ed. Assunção: El Lector, 2000, p. 129-138.
} 
Nos dois contos - princípio e fim da antologia delineia-se, alegoricamente, a contraposição entre os elementos que formam a sociedade paraguaia - o europeu decadente $\times 0$ indígena maltrapilho. Essa relação se estabelece, aparentemente, como antitética, mas entre a intensidade de 'contemplar-se' e a singularidade de 'não reconhecer-se' se divisam as marcas da hibridez - tanto no espelho que remete ao múltiplo como no cesto que revela um pertencimento comum. Nesse percurso, se instala o sofrimento de transitar transculturalmente e se esquadrinham os elementos fagocitados que encerram a experiência do dilaceramento de pertencer a vários mundos.

Dessa forma, pode-se afirmar que o conto Sesenta listas está estrategicamente posicionado entre "el espejo y el canasto", ou seja, entre o "ver-se e o estranhar-se". Nele encontramos um senhor, inválido e próximo da morte com "sus viejos huesos hambrientos de sol" (SL:129), mirando a chuva torrencial desde uma eternidade que, "sorda, era como um anticipo del espolvoreo de tierra sobre una sepultura" (SL:129).

Esse velho senhor espanhol chamado Don Celso sabe "que está viejo y achacoso; que la muerte espera ya ahí, a una vuelta en la esquina, con su silencio y su quietud sin término" (SL:130) e, ao aconchegar-se em um velho poncho, por ele carinhosamente chamado de "sesenta listas" passa a rememorar sua vida, detendo-se na insistente lembrança de um amor juvenil que também foi agasalhado pelo manto de Piribebuy.

Inebriado na ternura despertada pela lembrança daquela "muchacha de limpios ojos negros y prieto cuerpecito de ynambú que él tuvo en sus brazos apenas quince noches, que nunca más volvió a acordar sino para bromear con sus amigos" (SL:131), Don Celso passa a avaliar o impacto que causou na vida de outras mulheres porque "había simiente suya desparramada por los cuatro costados del país" (SL:133). Mas se detém naquela que, "había pensado humorísticamente, estrenara el poncho" (SL:130).

E esse velho senhor, de "ojos de un azul navegante" (SL:131) com o poncho sobre os ombros, faz reviver a presença de Clitemnestra - uma jovenzinha inocente e calada que recebeu um nome estrambótico que "una madre campesina y analfabeta había ido pescar Dios sabe donde..." (SL:131). Nesse primeiro encontro, embalado por sua condição de hóspede na casa do padrinho Don Olegario, universitário e fanfarrão, Don Celso se apresenta à jovem, burlão: - "Yo me llamo Agamenón" (SL:132).

A declaração, para desconcerto de quem acompanha o ritmo lírico das rememorações, fecha o prólogo - a introdução desse conto que remete à tragédia grega $\mathrm{A}$ Oresteia - também conhecida como Oréstia, Orestíada ou
A Trilogia de Orestes ${ }^{7}$ quebrando, de súbito, a empatia que o personagem havia conquistado ao relatar a história de um amor primaveril, consumado sob um "techo rasgado donde se veían las estrellas" (SL:132).

Esse corte abrupto ocorre devido à indignação provocada frente ao escárnio com que a garota é tratada. Ela, que parecia já conhecer "su almanaque de mujer de una casta resignada" (SL:132) é totalmente alheia à sátira que estão lhe infringindo. Agamenon-Celso está zombando da pequena mestiça, provavelmente agregada da fazenda de Don Olegario, uma garota que, comparada às irmãs era considerada como "la más pava y, además, tenía un nombre imposible" (SL:131).

A história narrada dentro do conto assume, portanto, nuances de esperpento ${ }^{8}$, pois a realidade, deformada, assume características absurdas e grotescas. Enquanto o teatro esperpêntico de Valle-Inclán tinha como ambientes tavernas, bordéis ou ambientes difusos e perigosos; nossos personagens se embrenham em "un viejo rancho perdido en el monte", "un pombero" onde "no había comodidad alguna. Ni un montón de paja" (SL:132). Entretanto, pode-se entrever algo mais nesse espelho social desfigurado: ele refrata nuances mais profundas e críticas - dessa sociedade. Clitemnestra é coisificada, reduzida a um títere nas mãos de seu sedutor.

Como se havia de pressupor, existia apenas um desfecho possível para essa encenação: "quince dias después llegó el momento de despedirse" (SL:132). Esse Agamenon-Celso não seria substituído por nenhum Egisto ao longo da vida. Clitemnestra continuaria fiel a ele por toda a vida, esperando resignada como se "todo estuviese previsto, todo apuntado de antemano con su exacto horario y contenido" (SL:132). E esse caso de amor-escárnio, alegoria do encontro do conquistador com os povos originários, teria, tal qual na tragédia grega, na morte, sua resolução. Agamenon-Celso haveria de enfrentar-se com seu próprio Orestes. A chuva, convertida em dilúvio, é a protagonista desse processo. Símbolo da fertilidade e da purificação, ela também remete à força e à cura. É ela quem lava o rosto enegrecido do homem que se resguarda da torrente enquanto tenta entregar o carvão na casa de

\footnotetext{
7 Trata-se de uma trilogia de peças teatrais de autoria do dramaturgo grego Ésquilo, composta pelas tragédias Agamemnon, Coéforas e Euménides. Nela, nos deparamos com a maldição da tragédia sobre a família de Atreu após o retorno da guerra de Troia. Agamenon, um dos comandantes do exército de Troia, casou-se com Clitenestra, tendo com ela quatro filhos. Por vingança, já que Agamenon havia matado sua filha Ifigenia e mantinha como amante a Cassandra, Clitenestra planeja o assassinato dos dois com a ajuda de Egisto (seu amante). Esse círculo de vingança se reproduz, outra vez, quando Orestes (filho de Agamenon com Clitenestra) decide matar a mãe e Egisto (o amante) para vingar o pai.

8 O esperpento é um gênero literário criado por Valle-Inclán, integrante da geração de 98. Trata-se de um modelo estético inspirado nas deformidades que os espelhos (côncavos e convexos) podem reproduzir, criando realidades distorcidas e grotescas. Predomina no esperpento a crítica social por meio da sátira e do escárnio.
} 
Don Celso, deixando entrever "los ojos azules, de un azul ingênuo". E o espanto diante da descoberta do nome incomum daquele trabalhador - Agamenon - "humilde, viril, tiznado e sonriente" desperta em Don Celso uma estranha simpatia. Como agrimensor, ele havia, em suas andanças pela República, tido inúmeras filhas:

Una hija con una buena muchacha de Guarambaré, que al verse desahuciada por la familia se suicidó. Dos con aquella maestra de Yuti, que perdió su empleo y tuvo que dedicarse a vender pastelitos y croquetas en un puestito suburbio... Otra hija con aquella solterona de Caaguazú, que se fue a Buenos Aires a tenerla y sabe Dios lo que habría sido de ella...Otra más con aquella viuda de Itauguá, casada después con un embarcadizo. Dos también con aquella muchacha de San Lorenzo, muerta al dar a luz a una tercera hija... Mujeres todos sus vástagos. Todas mujeres (SL:133).

Nenhum filho homem. Essa singularidade o fez casar-se, na expectativa que um matrimônio regularizado mudasse esse destino. Apesar disso, Don Celso viu perfilar o nascimento de sete meninas - "todas eran trabajadoras y honestas. Pero ocho mujeres en casa - diez contando las sirvientas - eran demasiadas mujeres, hasta para él" (SL:133). Talvez daí derive seu espanto quando descobre, em meio às risadas de suas filhas, que aquele "carbonero" que há um ano trazia, semanalmente, três sacos de carvão tinha uma mãe internada no hospital chamada Clitemnestra. Que essa mesma mãe estava internada com câncer, mas se recuperaria. Que ele era casado e tinha seis filhos homens. Que o filho mais velho também se chamava Agamenon. E essa enxurrada de informações trazida, com a mesma torrencialidade da chuva da tarde, calou a Don Celso. E o colocou enfermo.

Há uma confluência de símbolos entre a narrativa platiana e a tragédia grega. Em ambas, sob a égide da água, se desenlaçam os destinos. Agamenon é morto na banheira por Clitemnestra - recebendo assim o castigo pela morte da filha Ifigênia. Don Celso encontra sua enfermidade, também mortal, na mesma chuva que lhe proporciona o encontro com seu único filho varão. A água se apresenta, portanto, como elemento purificador do passado, mas também como divisa regeneradora do futuro.

Don Celso, analogicamente, está diante do espelho e do canasto e pode, concomitantemente, ver-se e estranhar-se. Suas memórias - de um passado nada glorioso - por menos confiáveis que sejam, parecem refletir sua honra ferida. Seu desgosto frente à incapacidade de gerar filhos homens dentro de uma estrutura patriarcal é acentuado pela proliferação de filhas mulheres que não buscavam outra coisa que não fosse as boas graças do patriarca:
Eran hacendosas, sabían cocinar e coser, poseían una cantidad de secretos para hacer más sabrosas las salsas, más lucientes el cristal y el bronce, más tersas las pecheras de las camisas. [...] Y cuando a las horas de comer presidía la mesa en que se escalonaban ocho cabezas femeninas de más vieja a más joven, se sentía vagamente en evidencia como dueño clandestino de un harén (SL:133-134).

Segundo Assmann (2011, p.72), quando se estabelece um nexo entre recordação e identidade, faz-se necessário atentar para a diferenciação entre o trabalho de rememoração e a manipulação oportunista da memória. No caso de Don Celso, percebe-se que não há fraude. Ele parece não escolher o que quer recordar e o que deseja manter obscuro para preservar sua idoneidade. A recordação da usurpação de Clitemnestra parece inserir-se em um processo de maturação onde a injustiça infligida finalmente se imprime no espelho. Junto dela, Don Celso vê desfilarem outras tantas imagens traumáticas que revelam sua covardia e seus abusos. É esse novo reflexo de si que lhe permite, finalmente, 'enxergar', por primeira vez, o carvoeiro. E ver-se nele.

Isso o lança diante, portanto, do incômodo "canasto", ou seja, daquilo ao qual se sabe pertencer, mas que devido ao caráter subalterno e ignominioso, é estrategicamente apagado e, ainda, atribuído ao Outro. E isso gera sofrimento, dilaceração. A esse processo, Kusch denomina "el miedo de ser nosotros mismos" (2000:08). Esse constrangimento em mostrar nossa verdade metaforizada nos elementos contidos no cesto: erva-mate, roupas sujas, sacos de estopa, verdura murcha - se dá porque "en el ángulo occidental lo de adentro dicho entre comillas es 'poco'. Y es preciso mucho más" (KUSCH, 2000, p. 26).

Segundo Pérez (2010), Kusch parte da percepção de que somos incapazes de assumir nossa selvageria. Para assumi-la, teríamos que "mirar el suelo, que es lo que sostiene la vida y es su apoyo espiritual", uma vez que "la cultura es un cultivo, y para saber qué cultivar hay que ver dónde está la semilla" (PÉREZ, 2010, p.33). Nesse sentido, o carbonero-canasto converte-se em um signo de resistência e autoafirmação do homem americano. É nele que está a semente híbrida que deverá ser disseminada.

Num jogo extremamente sutil, Josefina inverteu a lógica e desconstruiu, derridianamente, o sistema responsável pela existência de Don Celso e de Agamenon: o fruto da violação é que passará a assumir o papel de 'semeador' (antes prerrogativa do violador). Frente ao colonialismo que toma Clitemnestra e seu filho Agamenon como objetos manipuláveis - tanto no sentido econômico como humano - se levanta a rebeldia do próprio corpo que, ao gerar apenas 'varões semeadores' promove um lugar 
de reconciliação e reconhecimento identitário. As novas 'sementes' híbridas é que se alastrarão, apesar de toda a repugnância e medo que possam engendrar. Aí consiste o sentido da propagação de filhas mulheres (purismo) $\times$ filhos homens (hibridez) proposta na narrativa.

No conto Sesenta listas, o desajuste que promove toda essa descarga de consciência está localizado no objeto que empresta nome à narrativa - o poncho de Piribebuy. É aquele "fino tejido que ha perdido ha mucho del antiguo lustre" (SL:130) que colocará Don Celso diante de si, no espelho, fazendo-o reconhecer-se no Agamenon-canasto. Como objeto desencadeador das memórias, ele desempenha um papel metafórico, constituindo-se em uma linguagem outra que carrega em si os sentidos implícitos da narrativa, tornando-se o motor do relato. É responsável por abrigar o amor-escárnio, encenação do jovem Agamenon-Celso, mas também por lhe fazer recordar, à revelia de sua moral, os desenganos presenciados ao longo da vida e o abriga, afetivamente, dos calafrios dessas recordações. É também o objeto que o aqueceria em sua última convalescência e que, pelos desígnios do acaso, também abrigaria a Clitemnestra em sua saída do hospital.

O destino de Agamenon-Celso e Clitemnestra seria unido outra vez pela "trama adelgazada", "de amortecidos colores" do poncho que a filha mais velha do já defunto Don Celso doa ao prestativo carbonero. Largada em uma carreta, recém-saída do hospital, Clitemnestra se mantém na mesma ignorância de sempre. Nem sequer suspeita que esse último conforto lhe seja proporcionado pelo mesmo poncho que foi seu único luxo nupcial. $\mathrm{O}$ 'sesenta listas' funciona, portanto, como o catalisador das ações na narrativa e é, conforme argumentado, um artefato fagocitador. Suas múltiplas riscas remetem à intricada rede identitária que conjuga as Clitemnestras e os Agamenon-Celsos, fazendo aflorar sua hibridez. Esse novo sujeito cultural assomado na imagem das sessenta listras do poncho se perfaz em um 'diálogo entre dois eus' e entre duas temporalidades - um presente híbrido e um passado colonial.

Pertencente à tradição artesanal dos povos indígenas, o poncho é incorporado por Don Celso, tornando-se responsável por uma mudança em sua visão de mundo. Nele, estão as marcas da história, simultaneamente europeia e indígena, onde se inscrevem as múltiplas inscrições identitárias. Cada listra, nesse ínterim, resulta de um processo de articulação e negociação cultural da tradição ocidental e dos povos originários, fortalecendo a ideia defendida por Edward Said, para quem "[...] todas as culturas estão envolvidas umas com as outras, nenhuma é isolada e pura, todas são híbridas, heterogêneas, extraordinariamente diferenciadas e não monolíticas" (apud EAGLETON, 2005, p. 28).
Como o poncho, o sujeito cultural contemporâneo representado na figura de Agamenon, o filho de Clitemnestra, construiu-se por meio de contatos, diálogos e conflitos entre sua tradição e outras culturas. Essa promiscuidade étnica que se assenta sob o abrigo do "sesenta listas" faz emergir um cenário complexo que associa experiências e níveis de realidade conflituosos e contraditórios onde permanecem (e se metamorfoseiam) construtos culturais e identitários. Isso porque, nesse jogo ambivalente, Don Celso visualiza as bases culturais híbridas por ele protagonizadas, mas se sente desencorajado a explicitá-las. Seu desejo em reencontrar o 'carbonero' Agamenon jamais se concretiza. Esse movimento, no entanto, não se articula radicalmente. $\mathrm{O}$ estranhamento de ver-se naquele trabalhador, adivinhando nele sua futura descendência, somado ao revolvimento arqueológico - e sentimental - das memórias que explicitaram as nuances do encontro cultural, promove um espaço de interlocução onde o filho de Clitemnestra não é diminuído

Don Celso se echó nuevamente el poncho sobre los hombros para no enfriarse: sacó la botella de Piribebuy, puso dos dedos en el vasito, y asomándose a la puerta se lo tendió al carbonero. Este, sorprendido, sonrió al tomarlo. - Gracias che patrón. Tenía los dientes muy blancos, agradable la sonrisa, abierta de comisuras. Ante aquel hombre humilde y viril, tiznado y sonriente, Don Celso sintió subirle desde el plexo solar el calorcillo de una extraña simpatía (SL:135).

Percebe-se que essa simpatia compartilhada entre os personagens engendra no conto uma plataforma liminar onde o Outro não é depreciado. Ao contrário, alegoricamente, a narrativa aponta para uma dinâmica em que colonialidade e pós-colonialidade coexistem em um espaço relacional. Isso não significa, no entanto, o rompimento das relações de hierarquia e poder, mas suscita o reconhecimento daquilo que se tem em comum e que se corporifica na imagem do poncho.

Esse elo narrativo, lugar de memória e de reconhecimento identitário será o abrigo de Don Celso quando ele enfrenta o medo diante da morte e se depara com a simples verdade da vida de "ser nada más que un hombre sentado" que "reacomoda sobre sus muslos huesudos" enquanto, "despacio, casi amorosamente, pasa a lo largo de una lista sus dedos arrugados" (SL:130). Essa compreensão da velhice e da finitude, refletida na observação do tecido desgastado - "se va haciendo viejo el poncho" (SL:130) - permite a Don Celso enfrentar sua covardia e liberar a energia necessária para reconhecerse no Outro. E faz aflorar uma das bases da América profunda, uma "fuente de todas las verdades y de todo caos: la vida cotidiana. Nace un hijo, muere un familiar, 
triunfamos en un examen, tenemos amargura o alegría, todo esto qué es. Pues, debe ser 'estar no más' y es curioso que para ese estar no hay explicación" (KUSCH, 2000, p. 24).

Nesse reconhecimento último, Don Celso e Clitemnestra se unem outra vez pela verdade do envelhecimento e da morte. Diante de tais signos, a estrutura de poder e hierarquia que contrapôs e delineou, ao longo da vida, o destino deles - e de suas comunidades culturais - se desfaz. E as mesmas listras do poncho descolorido que velaram Don Celso passam a abrigar "la anciana morena y pequena, apenas canosa, de dulces ojos negros" (SL:138).

\section{Considerações finais}

A narrativa de Josefina Plá, engendrada transculturalmente, incorpora as formas fagocitadas que se solidificam na relação controversa entre o ser e o estar no mundo, entre as imagens que germinam do medo, do fedor e da neurose que perfazem as camadas da América profunda. Seus personagens buscam a sobrevivência em meio a uma sociedade hostil e excludente.

As origens desse fatalismo desolador e desolante podem ser vislumbradas na percepção de Josefina Plá sobre a importância que cobra o entorno sociocultural paraguaio em sua produção contística: "me identifiqué por tanto con el desheredamiento y la resignación de la mujer paraguaya, con la orfandad y desnudez de sus niñas, madres jóvenes, florecillas del camino. Todos los casos de mis cuentos son reales" (PLÁ, 1984).

Nesse momento, percebe-se que a contística de Josefina Plá se volta para a emergência e negociação do marginal, da minoria, do subalterno ou mesmo do diaspórico oriundo das comunidades originárias. Esvaziada de qualquer sentido épico, fechada em relatos e personagens de feitios cotidianos que nos incitam a reconhecer a prevalência da barbárie ${ }^{9}$, mas que, paradoxalmente, mesmo na sempre e contínua perda da "luz contra las tinieblas" (PLÁ, 1989) configura-se como um agenciamento político que sutura essas rasuras, concentrada como está no devir. Nesse processo, o leitor desempenha um papel fundamental, já que foi privado da tranquilidade contemplativa diante da coisa lida e se depara com a deriva, o fedor e a desumanização das criaturas platianas.

As vivências dos protagonistas desses enredos desolados e desoladores - encerram uma rede de sentidos

\footnotetext{
9 O termo barbárie é usado nesse momento sem a carga semântica imposta pelo jogo civilizado $\times$ bárbaro - próprio dos processos colonizadores. Não faz referência, portanto, aos povos 'carentes de civilidade' - para usar o paradigma da colonialidade, mas indica os índices de violência que ferem os direitos humanos em toda e qualquer comunidade cultural.
}

trágicos que pode ser ampliada a outras narrativas contemporâneas. Vivendo transculturalmente, eles se constituem como sujeitos que sofrem a agonia de viver em um entorno hostil que menospreza sua existência. Atravessados por diferentes visões de mundo, sem "encaixar-se" dentro da estrutura social, eles se veem despedaçados e arrojados em um espaço intersticial que, na maioria das vezes, não lhes pode ser favorável. Envoltos no sentimento desolador que nasce da percepção da impossibilidade de integração, esses seres estão à mercê dos revezes impostos pelos construtos culturais majoritários.

A análise da expressão do sofrimento infligido àqueles que, por serem frutos híbridos, encontram-se marginalizados e subalternizados é plasmado por Josefina Plá em diversas nuances - até mesmo desde a perspectiva do migrante colonizador, tal como foi analisado no conto Sesenta Listas - revelando a complexidade dessas relações e a potência de sua narrativa, sensível ao entrechoque cultural entre as comunidades originárias/mestiças $\times 0$ universo ocidentalizado.

\section{Referências}

ASSMANN, Aleida. Espaços da recordação. Trad. Paulo Soethe. Campinas: Editora da Unicamp, 2011.

BERND, Zilá. Mobilidades teóricas interamericanas. In: Revista Abecan [on line], v. 8, n. 2, p. 13-26, 2008.

BERND, Zilá. Por uma estética dos vestígios memoriais; releitura da literatura das Américas a partir dos rastros. Belo horizonte: Fino Traço, 2013.

BERND, Zilá. Vestígios memoriais: fecundando as literaturas das Américas. In: Revista Conexões, Porto Alegre, Universidade Federal do Rio Grande do Sul, v. 6, n. 6, p. 09-16, 2011.

BORDOLI DOLCI, Ramón Atílio. La problemática del tiempo y la soledad en la obra de Josefina Plá. 1984. 588f. Tese (Doutorado en Literatura Hispanoamericana) - Faculdad de Filología, Universidad de Santiago de Compostela.

CLIFFORD, James. Las culturas del viaje. Revista de Occidente, Madrid: Arce, n. 170-171, p. 45-74, 1997.

EAGLETON, Terry. A ideia de cultura. Trad. Sandra Castello Branco. São Paulo: Editora Unesp, 2005.

FERNÁNDEZ, Miguel Ángel. Interculturalidade e transculturalidade na literatura e na arte de Josefina Plá. Revista Raído. Dourados: UFGD, v. 6, n. 12, p. 33-42, jul./dez. 2012.

FERNÁNDEZ, Miguel Ángel. Introducción. In: Cuentos Completos. PLÁ, Josefina. Assunção: El lector, 2000.

FINNEGAN, Ruth. O significado da literatura em culturas orais. Disponível em: <http://www.letras.ufmg.br/vivavoz/ data1/arquivos/tradicaooral-site.pdf $>$. Acesso em: 17 de jul. 2013.

FOUCAULT, Michel. A ordem do discurso. Trad. Laura Fraga de Almeida Sampaio. São Paulo: Edições Loyola, 1999. 
HAVELOCK, Eric. A equação oralidade-escritura: uma fórmula para a mente moderna. In: OLSON, David; TORRANCE, Nancy. Cultura e oralidade. Trad. Valter Lellis Siqueira. São Paulo: Ática, 1995, p. 17-34.

KUSCH, Rodolfo. América profunda. In: Obras completas. Córdoba: Editorial Fundación Ross, 2000. t. II.

MATEO DEL PINO, Ángeles. El componente mitico y su función simbólica en la poesía erótica de Josefina Plá. 1994. Tese (Doutorado em Filología Hispânica) - Universidad de Las Palmas: Gran Canaria, 1994. Disponível em: <http://bibmdc. ulpgc.es/cdm/ref/collection/POSTULPGC/id/682>. Acesso em: 04 fev. 2014.

MENÉNDEZ PELAYO, Marcelino. Historias de la literatura hispanoamericana. Obras completas. Santander: Aldus, 1948. 2 v. p. 27-28.

PEIRÓ BARCO, José Vicente. Literatu.ra y sociedad: la narrativa paraguaya atual (1980-1995). Tese (Doutorado em Filologia Espanhola) - Faculdade de Filologia, Universidade de Educação à Distância. Madri, 2001. Disponível em: <http:// www.cervantesvirtual.com/autor/peiro-barco-jose-vicente--0/>. Acesso em: 10 abr. 2014.

PÉREZ, Alberto Julián. Rodolfo Kusch y su crítica a la razón occidental. Revista Mitologicas, Argentina: Centro Argentino de Etnología Americana, v. 25, p. 27-38, 2010.

PÉREZ-MARICEVICH, Francisco. Diccionario de la literatura paraguaya. Assunção: Biblioteca Colorados Contemporáneos, 1983.

PIGLIA, Ricardo. Formas breves. Trad. José Marcos Mariani de Macedo. São Paulo: Companhia das Letras, 2004.

PLÁ, Josefina. Acotaciones temporales. In: La pierna de Severina. Asunción: Ed. El Lector, 1984.
PLÁ, Josefina. Aborto. In: La muralla robada. Asunción: Universidad Católica - Biblioteca de Estudios Paraguayos, 1989. v. 28.

PLÁ, Josefina. Si puede llamarse prólogo. In: DEL PINO, Ángeles Mateo. Latido y tortura. Selección poética. Puerto del Rosario: Servicio de Publicaciones del Excmo. Cabildo Insular de Fuerteventura, 1995. p. 25-27.

PLÁ, Josefina. Cuentos completos. 2. ed. Asunción: El Lector, 2000.

QUIJANO, Alonso. Don Quijote y los molinos de viento en América Latina. In: Revista Estudos Avançados, São Paulo: USP, v. 19, n. 55, p. 09-31, 2005.

ROA BASTOS, Augusto. Cultura oral. Lectura crítica de la literatura americana. Caracas: Biblioteca Ayacucho, 1997.

ROA BASTOS, Augusto. Las culturas condenadas. Assunção: Fundación Roa Bastos, 2011.

RODRÍGUEZ ALCALÁ, Hugo. Historia de la literatura paraguaya. Assunção: El Lector, 1999.

SAGUIER, Rubens Bareiro. Encontro de culturas. In: MORENO, César Fernández (Org.). América latina em sua literatura. São Paulo: Perspectiva, 1979. p. 03-24.

SHOHAT, Ella; STAM, Robert. Crítica da imagem eurocêntrica. Trad. Mário Soares. São Paulo: Cosac Naif, 2006.

WALTER, Roland. Mobilidade cultural: o (não-)lugar na encruzilhada transnacional e transcultural. Revista Interfaces Brasil Canadá, Rio Grande: Abecan, n. 8, p. 37-56, 2008.

Recebido: 25 de abril de 2017

Aprovado: 25 de junho de 2017

Contato:

Maria Josele Bucco Coelho <joselebucco@gmail.com> 